\title{
Warrants for roundabouts and other traffic control devices
}

\author{
J D Sampson
}

There are many warrants for traffic signals, but no definitive warrant for roundabouts. Some references (e.g. TRB 2000) give guidelines, and refer to the capacities of roundabouts and TWSC (two-way stop control), but capacities address the upper limit of the control device, not the lower values which would justify, or warrant, a change in control. Other references refer to the need for a roundabout warrant but do not develop one. One paper by Sampson and Meijer (1999) discussed potential warrants, but no recommendation was made.

In this paper the role of roundabouts and mini-circles in filling the large gap between where stop control is no longer ideal, and where traffic signals are required, is examined.

It is found that there are many considerations in addition to volume or delay that need to be taken into account when deciding on whether to implement roundabout type control, but as a rule of thumb, if the average queue at a stop control exceeds two (2Q) during the peak hour, roundabouts will improve the traffic flow, and if the queue totals around ten or more (10Q), then the roundabout is likely to have reached its capacity.

\section{INTRODUCTION}

As part of a doctoral thesis, the author developed a queue-based traffic signal warrant (Sampson 1992; Sampson 1999). That 4Q / 6Q warrant was subsequently adopted in the South African Road Traffic Signs Manual (COTO 2001) as the official warrant for traffic signals in South Africa.

At the time (1980s) traffic circles had been phased out in South Africa (and in the USA and Australia) and roundabouts had yet to find international acceptance. While modern roundabouts were developed in the 1960s in the United Kingdom, they only appeared in the USA in the 1990s, and in South Africa they are still relatively rare.

At present therefore, existing warrants such as the MUTCD (US Department of Transport 2009) and SARTSM (COTO 2001) only consider the point at which the conversion from a stop-controlled intersection to a traffic signal is justified. Traffic signal warrants do not provide for roundabouts as an option.

Because of their safety and capacity benefits, however, roundabouts are becoming important traffic control devices and, for good reason, are becoming more and more common throughout the world.

In this paper, a warrant for mini-circles and roundabouts is developed. This is done by comparing the performance of stop street, all-way stop, mini-circle, modern roundabout and traffic signal control across a wide range of traffic volumes and geometric layouts.

\section{THE 4Q / $6 Q$ WARRANT FOR TRAFFIC SIGNALS (COTO 2001)}

For background, the 4Q / 6Q warrant is discussed. This is a conventional warrant which determines the point at which conversion from a stop to a signal becomes justified.

When developing the queue length warrant for traffic signals (Sampson 1992), it was found that to use traffic volumes as a warrant was not accurate, and the requirements for a signal depend on many more considerations than a simple traffic count would reveal.

Nor could "tolerable delay", which references suggested was an average delay of 57 seconds per vehicle at a stop street, be used as a warrant. This is because signals would be required long before they should be justified where side street traffic volumes are low, while at high side street traffic volumes traffic signals are needed long before the average delay of 57 seconds is reached.

It was therefore found that, for the above and many other reasons (such as accuracy, politics and ease of observation), the best measure to use for a warrant would be queue length. Conveniently so, because queue length is numerically equal to veh-hrs/hr (volume) of total delay, and total delay is directly aligned with cost. Queue can also be used to determine user costs.

Further research then led to the conclusion that, when a peak hour queue of vehicles or pedestrians reaches or exceeds
JOURNAL OF THE SOUTH AFRICAN INSTITUTION OF CIVIL ENGINEERING ISSN 1021-2019 Vol 62 No 2, June 2020, Pages 31-38, Paper 0701

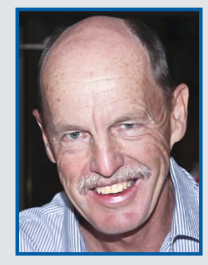

DR JOHN SAMPSON (Pr Eng, FSAAE, FSAICE) has a BSc Civil Engineering (Wits), MSC Transportation Engineering (California, Berkeley), BCom (UNISA) and a PhD (Wits). His experience includes Managing Director of TTT Africa, Partner and Director of Jeffares \& Green Consulting Engineers (now JG Afrika), Professor at the University of

Pretoria, Deputy City Engineer of City of Johannesburg, Chairperson of the Board of Directors of the Road Traffic Management Corporation, Director of the Road Traffic Infringement Agency, Expert on Gauteng Transport Commission and Member of the Gauteng Integrated Transport Master Plan Steering Committee.

Contact details

Consultant: Traffic and Transportation

TTT Africa

P0 Box 1109

Sunninghill 2157

Sandton

South Africa

T: +27112312298

E: sampsonj@tttafrica.co.za
Keywords: traffic signals, roundabouts, warrants, queue, delay, stop street, all-way (4-way) stop, mini-circle 
four on average, this was the point at which traffic signals could be justified. In addition, if the sum of all the queues of vehicles and pedestrians on average throughout a full hour exceeded six, this would also justify signals. This became the 4Q / 6Q warrant (Sampson 1992; COTO 2001). Note that this is a peak hour warrant.

As was stated in the Introduction, the 4Q / 6Q warrant however only considers the point at which a side road stop control should be converted to an intersection signal control. This research is now extended to include roundabouts.

\section{GUIDELINES FOR ROUNDABOUTS}

Before analysing the technical performance of roundabouts compared to other control devices, conventional guidelines are considered.

Roundabouts equalise the priority of all approach roads. No matter how minor the intersecting road may be, it is afforded the same priority on entry as any of the major routes. Furthermore, all vehicles must slow and take gaps on approaching the roundabout, and priority cannot be given to any movement without violating the roundabout operational principles (e.g. once a traffic signal or stop street is introduced at a roundabout, it ceases to operate as a roundabout).

With these limitations in mind, the following is a summary of the Guidelines for the Location of Roundabouts, extracted from local and international literature and as contained in Roundabouts (Traffic Circles) as Intersection Control Devices on

Provincial Roads (PWV Consortium 2001).

The best locations for roundabouts are as follows:

- Intersections where safety would otherwise be a problem

- Intersections where environmental enhancement or landscaping is required

- Intersections where traffic signal maintenance or the availability of power is a problem

- Where permanent traffic control without enforcement is necessary

- Where there are four-way or all-way stops

- Where the road standard or speed limit changes (e.g. where an arterial road changes to collector / local street status)

- Where urban and rural roads meet (e.g. entrance to towns) or where commercial/industrial and residential areas meet
- In suburban areas where traffic calming is required

- At intersections with high turning movements

- Where U-turns are prevalent or desirable

- Where three or more stages are required at traffic signals

- At intersections with more than four legs

- At Y-junctions or other junctions with awkward geometry (e.g. sharp change in direction)

- With other roundabouts in a network where intersection spacing is too close for signal coordination to be achieved.

The worst locations for roundabouts are as follows:

- Where main road and side road traffic flows differ greatly

- Where minor crossroads enter major routes when a stop or yield street would suffice

- In signalised coordinated networks where they would break up the platoon flow

Where traffic signals will soon be required.

As is the case with all intersection control devices, roundabouts should be avoided on roads with steep slopes or where the intersection is not visible. Longer "flat" areas are required for roundabouts compared with other intersection types, making them less suitable on steep grades.

\section{WARRANT DEVELOPMENT}

\section{Intersection control devices}

The research that follows contrasts and compares the full range of intersection control devices, namely conventional stops, all-way stops, mini-circles, modern roundabouts and traffic signals.

To do this, an intersection simulation software program called AutoJ (Sampson 2018) is used. AutoJ is based primarily on the formulae in the Highway Capacity Manual (TRB 2010).

For a given set of geometric and traffic volume conditions, AutoJ compares the $\mathrm{V} / \mathrm{C}$ (volume to capacity ratio), delay, queue and level of service performance of five forms of priority control and 21 different traffic signal staging and phasing options simultaneously. It does this for vehicles, pedestrians and bicycles for up to three periods (typically AM, PM and off-peak hours) at a time.
To compare controls, AutoJ summarises the performance of each in a table (see Appendix A on page 38).

\section{Typical intersection geometry}

The investigation is limited to a maximum of two lanes on each approach as roundabouts with three approach lanes are rare and require detailed site-specific investigation.

The number of approach lanes tested include $2 \times 2,2 \times 1$ and $1 \times 1$. A $2 \times 1$ cross-junction would be as follows:

- Main road: 2 lanes in each direction, with 1 right-turning lane added if traffic signals are considered, 2 approach and 2 circulatory lanes if a roundabout is considered, and 1 approach lane and 1 "circulatory” lane if a mini-circle is considered.

- Side road: 1 lane in each direction, with 1 right-turning lane added if traffic signals are considered, 1 approach and 2 circulatory lanes (for main road traffic) if a roundabout is considered, and 1 approach lane if a mini-circle is considered.

Geometrically this favours the traffic signal, as the addition of a right-turn bay means there are more approach lanes for that option. Nevertheless, it will be shown that even with that advantage, the traffic signal only becomes the optimal control at very high volumes.

\section{Traffic volumes}

Many volume combinations were considered, with the two-way main road ranging from 0 to 3600 vehicles per hour (with a 60:40 split), the "high" side street volume ranging from 0 to 1400 per hour, and the other side street approach set at 100 vehicles per hour.

For the $2 \times 1$ geometry, typically a suburban collector side street entering a minor arterial road, the turning volumes on the main road were taken as $10 \%$ left and right, and $80 \%$ straight, while the turning volumes on the side road were taken as $45 \%$ left and right and 10\% straight.

For the $1 \times 1$ geometry, typically two collector streets joining, the turning volumes on the main road were taken as $20 \%$ left and right, and $60 \%$ straight, while the turning volumes on the side road were taken as $33 \%$ left, right and straight.

For the $2 \times 2$ geometry, typically two minor arterials intersecting, the turning volumes on both the main road and the side road were taken as $20 \%$ left and right, and $60 \%$ straight. 


\section{RESULTS}

Tables 1 to 5 are a summary of the most important findings. The first three, i.e. Tables 1, 2 and 3, have the same geometric configuration $(2 \times 1)$ but different measures of performance (delay, queue and level of service based on $\mathrm{V} / \mathrm{C}$ ). Tables 2,4 and 5 have the same measure of performance (queue), but different geometric configurations $(2 \times 1,1 \times 1$ and $2 \times 2)$.

\section{Measures of performance}

There are various performance measures that can be considered when determining the efficiency of a control device. Most commonly these are:

- Volume to capacity ratio (V/C)

- Average delay (seconds per vehicle)

- Total delay (vehicle-hours per hour)

- Queues

Level of service.

When developing the warrant, all these measures were considered across the full range of traffic volumes and control devices, and all are presented in the Tables. All-way stops, however, do not appear in the Tables, as they are never the preferred control under any circumstances.

\section{Optimal performance}

To easily see where a control device is optimal, the blocks in Tables 1, 2, 4 and 5 are coloured as follows:
- Stop
green
- Mini-circle
yellow
- Roundabout
pink
- Traffic signal blue.

Table 3 is coloured differently as will be described.

\section{Measure 1: Maximum delay $(2 \times 1)$}

The first comparison is the maximum hourly average delay experienced by the worst affected movement in a $2 \times 1$ geometric situation.

The black line in Table 1 is the dividing line between stop control and traffic signal control if mini-circles and roundabouts are not considered. It was previously indicated that when developing the 4Q / 6Q warrant, one consideration for warranting signals was when the average delay at the stop exceeded 57 seconds (Sampson 1992). Even though this was not used as a warrant, and it is not easy to see in Table 1, the black line appears approximately where the 57 second cut-off would be.

For reasons stated earlier, maximum delay is not the best criterion to be used when warranting a control device. Were
Table 1 Maximum delay to worst affected movement $(2 \times 1)$

\begin{tabular}{|c|c|c|c|c|c|c|c|c|c|c|}
\hline 1 & High side & \multicolumn{9}{|c|}{ Maximum delay (sec/veh) $(2 \times 1)$} \\
\hline stop & \multirow{4}{*}{1400} & 306 & 858 & 1275 & & & & & & \\
\hline mini & & 244 & 512 & 736 & & & & & & \\
\hline r-about & & 236 & 477 & 683 & & & & & & \\
\hline signal & & 27 & 33 & 297 & & & & & & \\
\hline stop & \multirow{4}{*}{1200} & 71 & 686 & 1173 & 1465 & & & & & \\
\hline mini & & 37 & 286 & 548 & 767 & & & & & \\
\hline r-about & & 36 & 244 & 485 & 690 & & & & & \\
\hline signal & & 27 & 27 & 36 & 445 & & & & & \\
\hline stop & \multirow{4}{*}{1000} & 25 & 446 & 1030 & 1381 & 1590 & & & & \\
\hline mini & & 13 & 36 & 283 & 547 & 780 & & & & \\
\hline r-about & & 14 & 30 & 208 & 454 & 665 & & & & \\
\hline signal & & 27 & 24 & 22 & 20 & 28 & & & & \\
\hline stop & \multirow{4}{*}{800} & 16 & 86 & 815 & 1254 & 1516 & 1671 & & & \\
\hline $\operatorname{mini}$ & & 9 & 12 & 25 & 272 & 617 & 847 & & & \\
\hline r-about & & 10 & 12 & 20 & 100 & 364 & 590 & & & \\
\hline signal & & 27 & 22 & 19 & 17 & 20 & 123 & & & \\
\hline stop & \multirow{4}{*}{600} & 13 & 19 & 458 & 1043 & 1392 & 1599 & 1720 & & \\
\hline $\operatorname{mini}$ & & 7 & 8 & 11 & 54 & 431 & 695 & 883 & & \\
\hline r-about & & 8 & 9 & 10 & 13 & 24 & 163 & 419 & & \\
\hline signal & & 24 & 18 & 15 & 19 & 22 & 25 & 498 & & \\
\hline stop & \multirow{4}{*}{400} & 11 & 12 & 26 & 620 & 1144 & 1454 & 1637 & 1743 & \\
\hline mini & & 6 & 7 & 9 & 18 & 219 & 521 & 737 & 898 & \\
\hline r-about & & 7 & 7 & 8 & 8 & 9 & 11 & 17 & 50 & \\
\hline signal & & 20 & 14 & 18 & 21 & 24 & 25 & 243 & 774 & \\
\hline stop & \multirow{4}{*}{200} & 10 & 10 & 11 & 17 & 400 & 1020 & 1385 & 1695 & 1879 \\
\hline mini & & 5 & 6 & 8 & 12 & 37 & 322 & 569 & 754 & 898 \\
\hline r-about & & 7 & 7 & 7 & 8 & 8 & 10 & 12 & 18 & 45 \\
\hline \multirow[t]{4}{*}{ signal } & & 13 & 19 & 23 & 23 & 23 & 23 & 158 & 567 & 938 \\
\hline & & 400 & 800 & 1200 & 1600 & 2000 & 2400 & 2800 & 3200 & 3600 \\
\hline & & \multicolumn{9}{|c|}{ Main 2-way (veh/hr) } \\
\hline & & & & Mini circ & 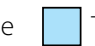 & Traffic sigr & & Roundab & & \\
\hline
\end{tabular}


it to be used, however, it is interesting to see that a stop control is never optimal (no block in Table 1 is coloured green). This is because users of a mini-circle or roundabout will not need to stop in low flow conditions, hence will always experience less delay than at a stop street.

\section{Measure 2: Queue $(2 \times 1)$}

Table 2 is the result when queue length is used as the criterion to choose a control device. The numbers in Table 2 are the total queue length (or total delay in vehiclehours per hour; whichever is preferred as a measure, they are numerically equal).

As above, the black line is the split between a stop and traffic signal control if mini-circles or roundabouts are not considered. It can be noted that when the queue length exceeds four at the stop, traffic signals are warranted, thus confirming the $4 \mathrm{Q}$ warrant.

In Table 2, the inclusion of mini-circles and roundabouts changes the $4 \mathrm{Q}$ warrant picture considerably. Clearly, mini-circles and roundabouts provide the optimal solution over a wide range between the stop and signal options. Neglecting the inclusion of these options, as the 4Q / 6Q warrant does, will mean that the optimal control will not be considered. An important conclusion of this research therefore is that previous warrants need to be revised to include the mini-circle and roundabouts as options.

Looking more closely at Table 2 , a minicircle or roundabout appears to become justified when the queue at the stop exceeds two vehicles (2Q).

The upper limit of queue before a signal is warranted is less obvious because, as the main road volumes increase, the length of queue required to warrant signals also increases (from eight to twelve). For warrant purposes, when the roundabout queues exceed approximately ten (10Q), a traffic signal control may perform better.

Note, however, that this is purely a peak-hour consideration. When volumes drop off-peak, the roundabout will perform better than the signal.

\section{Measure 3: Level of service $(2 \times 1)$}

In Table 3, the level of service, based on the volume to capacity ratio, is coloured as follows:

- LoS $\mathrm{A}$ and $\mathrm{B}(\mathrm{V} / \mathrm{C}<0.8)=$ green

- $\operatorname{LoS} \mathrm{C}$ and $\mathrm{D}(\mathrm{V} / \mathrm{C}<0.95)=$ blue

- $\mathrm{LoS} \mathrm{E}(\mathrm{V} / \mathrm{C}<1.0)=$ yellow

- $\operatorname{LoS} F=$ red
Table 2 Queue $(2 \times 1)$

\begin{tabular}{|c|c|c|c|c|c|c|c|c|c|c|}
\hline 2 & High side & \multicolumn{9}{|c|}{ Total queue / delay (veh-hrs/hr) $(2 \times 1)$} \\
\hline stop & \multirow{4}{*}{1400} & 93.8 & 302.6 & 431.1 & & & & & & \\
\hline $\operatorname{mini}$ & & 95.6 & 201.7 & 375.0 & & & & & & \\
\hline r-about & & 92.7 & 187.1 & 268.5 & & & & & & \\
\hline signal & & 6.0 & 9.8 & 61.5 & & & & & & \\
\hline stop & \multirow{4}{*}{1200} & 17.4 & 197.8 & 326.3 & 406.0 & & & & & \\
\hline $\operatorname{mini}$ & & 13.0 & 97.3 & 228.3 & 433.1 & & & & & \\
\hline r-about & & 12.9 & 83.2 & 164.4 & 234.8 & & & & & \\
\hline signal & & 5.2 & 8.7 & 13.6 & 116.4 & & & & & \\
\hline stop & \multirow{4}{*}{1000} & 6.0 & 92.9 & 221.4 & 301.1 & 355.5 & & & & \\
\hline $\operatorname{mini}$ & & 4.5 & 11.8 & 87.3 & 281.1 & 475.0 & & & & \\
\hline r-about & & 4.9 & 9.9 & 60.4 & 130.3 & 191.9 & & & & \\
\hline signal & & 4.6 & 7.8 & 10.5 & 13.2 & 16.1 & & & & \\
\hline stop & \multirow{4}{*}{800} & 3.4 & 12.7 & 116.5 & 196.3 & 249.2 & 300.2 & & & \\
\hline $\operatorname{mini}$ & & 2.7 & 4.3 & 9.7 & 122.1 & 317.1 & 502.6 & & & \\
\hline r-about & & 3.1 & 4.5 & 7.1 & 26.1 & 86.7 & 142.0 & & & \\
\hline signal & & 4.2 & 6.9 & 9.1 & 11.2 & 13.4 & 29.3 & & & \\
\hline stop & \multirow{4}{*}{600} & 2.2 & 3.1 & 37.1 & 91.4 & 143.6 & 194.5 & 243.4 & & \\
\hline $\operatorname{mini}$ & & 1.9 & 2.9 & 4.8 & 18.3 & 154.8 & 338.0 & 520.5 & & \\
\hline r-about & & 2.2 & 3.2 & 4.3 & 5.9 & 9.2 & 35.0 & 86.7 & & \\
\hline signal & & 3.7 & 5.9 & 7.6 & 9.2 & 10.8 & 12.9 & 37.7 & & \\
\hline stop & \multirow{4}{*}{400} & 1.4 & 1.6 & 2.5 & 32.7 & 59.9 & 94.3 & 138.1 & 204.4 & \\
\hline $\operatorname{mini}$ & & 1.4 & 2.2 & 3.5 & 7.0 & 76.0 & 213.4 & 356.7 & 587.1 & \\
\hline r-about & & 1.7 & 2.5 & 3.4 & 4.5 & 5.9 & 8.0 & 12.2 & 29.9 & \\
\hline signal & & 3.2 & 4.8 & 5.9 & 6.9 & 8.1 & 9.7 & 23.6 & 64.5 & \\
\hline stop & \multirow{4}{*}{200} & 0.8 & 0.9 & 1.0 & 1.4 & 11.5 & 36.0 & 73.3 & 131.5 & 180.2 \\
\hline $\operatorname{mini}$ & & 1.0 & 1.8 & 2.8 & 4.8 & 14.8 & 132.7 & 275.3 & 479.7 & 716.9 \\
\hline r-about & & 1.2 & 2.0 & 2.8 & 3.8 & 5.0 & 6.5 & 8.8 & 13.5 & 32.0 \\
\hline \multirow[t]{4}{*}{ signal } & & 2.4 & 3.3 & 4.0 & 5.0 & 6.2 & 8.2 & 15.2 & 55.0 & 90.3 \\
\hline & & 400 & 800 & 1200 & 1600 & 2000 & 2400 & 2800 & 3200 & 3600 \\
\hline & & \multicolumn{9}{|c|}{ Main 2-way (veh/hr) } \\
\hline & & & Min & circle & Traffic & signal & Rour & dabout & Stop & \\
\hline
\end{tabular}


Table 3 Level of service $(2 \times 1)$

\begin{tabular}{|c|c|c|c|c|c|c|c|c|c|c|}
\hline 3 & $\begin{array}{l}\text { high side } \\
\text { (veh/hr) }\end{array}$ & \multicolumn{9}{|c|}{ Level of service based on V/C $(2 \times 1)$} \\
\hline stop & \multirow{4}{*}{1400} & 1.13 & 1.75 & 2.94 & & & & & & \\
\hline $\operatorname{mini}$ & & 1.11 & 1.33 & 1.59 & & & & & & \\
\hline r-about & & 1.10 & 1.29 & 1.52 & & & & & & \\
\hline signal & & 0.58 & 0.73 & 1.10 & & & & & & \\
\hline stop & \multirow{4}{*}{1200} & 0.97 & 1.50 & 2.52 & 4.26 & & & & & \\
\hline $\operatorname{mini}$ & & 0.95 & 1.14 & 1.36 & 1.63 & & & & & \\
\hline r-about & & 0.94 & 1.11 & 1.30 & 1.53 & & & & & \\
\hline signal & & 0.50 & 0.54 & 0.84 & 1.21 & & & & & \\
\hline stop & \multirow{4}{*}{1000} & 0.81 & 1.25 & 2.10 & 3.55 & 6.05 & & & & \\
\hline $\operatorname{mini}$ & & 0.79 & 0.95 & 1.14 & 1.36 & 1.65 & & & & \\
\hline r-about & & 0.79 & 0.92 & 1.08 & 1.27 & 1.49 & & & & \\
\hline signal & & 0.41 & 0.47 & 0.54 & 0.61 & 0.84 & & & & \\
\hline stop & \multirow{4}{*}{800} & 0.65 & 1.00 & 1.68 & 2.84 & 4.84 & 8.30 & & & \\
\hline $\operatorname{mini}$ & & 0.63 & 0.76 & 0.91 & 1.13 & 1.44 & 1.76 & & & \\
\hline r-about & & 0.63 & 0.74 & 0.87 & 1.02 & 1.20 & 1.41 & & & \\
\hline signal & & 0.34 & 0.41 & 0.47 & 0.56 & 0.71 & 1.00 & & & \\
\hline stop & \multirow{4}{*}{600} & 0.49 & 0.75 & 1.26 & 2.13 & 3.63 & 6.23 & 10.74 & & \\
\hline $\operatorname{mini}$ & & 0.47 & 0.57 & 0.72 & 0.98 & 1.25 & 1.53 & 1.82 & & \\
\hline r-about & & 0.47 & 0.55 & 0.65 & 0.76 & 0.90 & 1.05 & 1.24 & & \\
\hline signal & & 0.27 & 0.34 & 0.40 & 0.52 & 0.69 & 0.87 & 1.27 & & \\
\hline stop & \multirow{4}{*}{400} & 0.32 & 0.50 & 0.84 & 1.42 & 2.42 & 4.15 & 7.16 & 12.44 & \\
\hline $\operatorname{mini}$ & & 0.32 & 0.41 & 0.63 & 0.86 & 1.09 & 1.34 & 1.59 & 1.85 & \\
\hline r-about & & 0.31 & 0.37 & 0.43 & 0.51 & 0.60 & 0.70 & 0.83 & 0.97 & \\
\hline signal & & 0.20 & 0.27 & 0.34 & 0.40 & 0.69 & 0.83 & 1.07 & 1.58 & \\
\hline stop & \multirow{4}{*}{200} & 0.16 & 0.25 & 0.42 & 0.71 & 1.21 & 2.08 & 3.58 & 9.78 & 999.99 \\
\hline $\operatorname{mini}$ & & 0.18 & 0.36 & 0.55 & 0.75 & 0.95 & 1.16 & 1.38 & 1.61 & 1.85 \\
\hline r-about & & 0.16 & 0.19 & 0.29 & 0.39 & 0.50 & 0.61 & 0.72 & 0.84 & 0.96 \\
\hline \multirow[t]{4}{*}{ signal } & & 0.13 & 0.20 & 0.28 & 0.37 & 0.56 & 0.87 & 1.02 & 1.33 & 1.86 \\
\hline & & 400 & 800 & 1200 & 1600 & 2000 & 2400 & 2800 & 3200 & 3600 \\
\hline & & \multicolumn{9}{|c|}{ Main 2-way (veh/hr) } \\
\hline & OS $A$ and $B$ & $/ / C<0$ & & $S C$ and & $\mathrm{D}(\mathrm{V} / \mathrm{C}<$ & & LOS E & $/ / C<1.0)$ & & \\
\hline
\end{tabular}

Table 3 is different from the other Tables in that LoS is colour-coded and not the preferred control. Because traffic signals have the greatest capacity, they will always have the lowest $\mathrm{V} / \mathrm{C}$ regardless of volume. If Table 3 were colour-coded in the same way as the others therefore, it would be all blue.

For that and other reasons, V/C is not a suitable measure for a warrant (there is therefore no black line to indicate the stop / traffic signal boundary). It is, however, suitable to determine when the capacity of the different control devices is reached.

In Table 3 it can be noted that there is a large area of overlap where the stop, minicircle, roundabout and traffic signal have a similar level of service, indicating that there is a large range over which any of the controls could be appropriate from an LoS viewpoint.

\section{Measure 4: Queue $(1 \times 1)$}

Table 2 provided the queue warrant with a $2 \times 1$ geometric configuration. Tables 4 and 5 give the queue warrant with a $1 \times 1$ and $2 \times 2$ geometric layout.

In this case of single lane approaches, as expected, the mini-circle, being smaller and causing less delay, is generally slightly better than the roundabout.

However, similar threshold values as in the $2 \times 1$ case can be observed, i.e. that the mini-circle / roundabout is preferred when the queue at the stop reaches around two (2Q), and the traffic signal becomes warranted when the total queue at the mini-circle / roundabout reaches about ten (10Q).

\section{Measure 5: Queue $(2 \times 2)$}

The optimal control using queue as a criterion with a $2 \times 2$ geometric configuration is shown in Table 5.

In a multi-lane situation, it would be expected that a two-lane roundabout would perform better than a single lane mini-circle, and this is indeed the case.

Again, it is found that the roundabout is preferred to a stop control at a queue length of about two (2Q), while the traffic signal becomes the preferred device a little later than in the single-lane cases, when the queue at the roundabout exceeds between ten to fifteen (10Q).

\section{CONCLUSIONS AND RECOMMENDATIONS}

There are several recommendations and conclusions that can be made 
resulting from this research. The most important are:

- Internationally, traffic signal warrants need to be amended, because when a stop street reaches capacity, the traffic signal should not automatically be considered as the next best option.

- When a stop control is not functioning optimally, or when the queue exceeds two on average at the stop throughout the hour (2Q), this is an indication that a mini-circle or roundabout should be considered.

- When the total of queues waiting on approaches to a roundabout reach ten (10Q) in the peak hour, traffic signals may be considered.

- Mini-circles and roundabouts have therefore been found to provide the optimum control in the wide range of situations ranging between very low and very high intersection volumes.

- Mini-circles are slightly better than roundabouts in single-lane approach, low main road volume situations, while roundabouts are better for multi-lane, higher main road volume intersections.

- There is significant overlap where more than one device will perform well. While the colour coding in Tables 1, 2, 4 and 5 tends to emphasise a clear division between one control and another, examination of the numbers shows that different controls perform similarly over a wide range. This is most easily seen in Table 3 .

- Queue length was found to be the best indicator of when a stop should be converted to a traffic signal (Sampson 1992), and this research confirms that it is also the best measure to use as a warrant when considering roundabouts.

- There are, however, additional considerations for roundabouts, as indicated in the Guidelines quoted.

- In the research for AutoJ (Sampson 2018), to take into account that the control device must operate over 24 hours and not just the peak hour, a performance index was developed (Appendix A). This is a more sophisticated approach than using a simple single-number test during one hour, as suggested by a warrant. The warrant derived in this paper can, however, be used as the basis for the need for further investigation.

- Regardless of the technical calculations above, engineering judgement remains an important consideration, because there are situations where roundabouts may not be preferred, e.g. when a traffic
Table 4 Queue $(1 \times 1)$

\begin{tabular}{|c|c|c|c|c|c|c|c|c|c|c|}
\hline 4 & $\begin{array}{l}\text { High side } \\
\text { (veh/hr) }\end{array}$ & \multicolumn{9}{|c|}{ Total queue / delay (veh-hrs/hr) $(1 \times 1)$} \\
\hline stop & \multirow{4}{*}{1400} & 214.6 & 427.1 & 555.6 & & & & & & \\
\hline $\operatorname{mini}$ & & 73.4 & 191.4 & 408.2 & & & & & & \\
\hline r-about & & 73.0 & 163.5 & 360.6 & & & & & & \\
\hline signal & & 6.7 & 12.3 & 26.0 & & & & & & \\
\hline stop & \multirow{4}{*}{1200} & 141.9 & 322.2 & 450.6 & & & & & & \\
\hline $\operatorname{mini}$ & & 9.8 & 69.1 & 263.8 & & & & & & \\
\hline r-about & & 10.3 & 57.4 & 216.3 & & & & & & \\
\hline signal & & 5.7 & 10.2 & 15.8 & & & & & & \\
\hline stop & \multirow{4}{*}{1000} & 71.0 & 217.2 & 345.7 & 417.7 & & & & & \\
\hline $\operatorname{mini}$ & & 4.2 & 8.6 & 112.1 & 320.2 & & & & & \\
\hline r-about & & 4.7 & 8.3 & 65.6 & 268.3 & & & & & \\
\hline signal & & 5.0 & 8.7 & 12.6 & 241.6 & & & & & \\
\hline stop & \multirow{4}{*}{800} & 9.3 & 112.8 & 240.7 & 312.6 & & & & & \\
\hline $\operatorname{mini}$ & & 2.7 & 4.2 & 16.9 & 164.3 & & & & & \\
\hline r-about & & 3.1 & 4.6 & 10.6 & 131.8 & & & & & \\
\hline signal & & 4.4 & 7.4 & 10.3 & 16.6 & & & & & \\
\hline stop & \multirow{4}{*}{600} & 2.8 & 37.9 & 135.8 & 207.6 & 254.8 & & & & \\
\hline $\operatorname{mini}$ & & 1.9 & 2.9 & 5.7 & 88.8 & 232.2 & & & & \\
\hline r-about & & 2.3 & 3.4 & 5.8 & 66.0 & 207.8 & & & & \\
\hline signal & & 3.9 & 6.2 & 8.3 & 10.9 & 99.2 & & & & \\
\hline stop & \multirow{4}{*}{400} & 1.5 & 2.4 & 32.6 & 102.7 & 147.9 & & & & \\
\hline $\operatorname{mini}$ & & 1.4 & 2.2 & 3.8 & 16.9 & 157.3 & & & & \\
\hline r-about & & 1.7 & 2.7 & 4.3 & 12.7 & 138.8 & & & & \\
\hline signal & & 3.2 & 4.9 & 6.2 & 7.8 & 23.1 & & & & \\
\hline stop & \multirow{4}{*}{200} & 0.8 & 1.0 & 1.4 & 3.6 & 40.9 & 84.0 & & & \\
\hline $\operatorname{mini}$ & & 1.0 & 1.8 & 3.0 & 6.1 & 71.2 & 223.6 & & & \\
\hline r-about & & 1.3 & 2.2 & 3.4 & 6.4 & 60.3 & 209.1 & & & \\
\hline \multirow[t]{4}{*}{ signal } & & 2.4 & 3.3 & 4.0 & 5.2 & 7.9 & 61.1 & & & \\
\hline & & 400 & 800 & 1200 & 1600 & 2000 & 2400 & 2800 & 3200 & 3600 \\
\hline & & \multicolumn{9}{|c|}{ Main 2-way (veh/hr) } \\
\hline & & & & circle & Traffic & signal & Rour & dabout & Stop & \\
\hline
\end{tabular}


Table 5 Total delay / queue $(2 \times 2)$

\begin{tabular}{|c|c|c|c|c|c|c|c|c|c|c|}
\hline 5 & High side & \multicolumn{9}{|c|}{ Total queue / delay (veh-hrs/hr) $(2 \times 2)$} \\
\hline stop & \multirow{4}{*}{1400} & 93.4 & 310.3 & 488.5 & 595.8 & 659.9 & 707.9 & 747.0 & 824.0 & \\
\hline $\operatorname{mini}$ & & 62.6 & 230.4 & 446.6 & 650.5 & 844.3 & 1035.0 & 1306.4 & 1586.0 & \\
\hline r-about & & 4.4 & 6.0 & 13.3 & 140.8 & 293.5 & 519.8 & 740.4 & 950.2 & \\
\hline signal & & 6.1 & 8.7 & 12.0 & 16.0 & 25.6 & 34.8 & 80.3 & 210.8 & \\
\hline stop & \multirow{4}{*}{1200} & 18.6 & 224.7 & 383.5 & 489.9 & 553.5 & 602.1 & 641.6 & 718.7 & \\
\hline $\operatorname{mini}$ & & 8.9 & 85.8 & 303.6 & 509.1 & 704.4 & 896.5 & 1169.2 & 1450.1 & \\
\hline r-about & & 3.6 & 4.8 & 7.3 & 64.4 & 207.1 & 357.9 & 570.7 & 782.8 & \\
\hline signal & & 5.5 & 8.0 & 10.9 & 14.0 & 22.4 & 28.8 & 42.6 & 134.8 & \\
\hline stop & \multirow{4}{*}{1000} & 6.2 & 140.0 & 278.4 & 384.8 & 446.8 & 496.2 & 536.1 & 613.4 & 725.8 \\
\hline $\operatorname{mini}$ & & 4.1 & 9.4 & 152.0 & 359.3 & 556.4 & 750.2 & 1024.6 & 1307.1 & 1582.0 \\
\hline r-about & & 3.0 & 4.0 & 5.6 & 11.3 & 120.1 & 264.5 & 412.3 & 603.1 & 810.0 \\
\hline signal & & 5.0 & 7.3 & 9.7 & 12.2 & 19.5 & 24.4 & 32.6 & 65.4 & 186.7 \\
\hline stop & \multirow{4}{*}{800} & 3.5 & 55.7 & 178.9 & 279.7 & 339.7 & 390.0 & 430.5 & 508.1 & 620.6 \\
\hline $\operatorname{mini}$ & & 2.6 & 4.4 & 60.7 & 205.8 & 398.6 & 594.6 & 871.0 & 1155.4 & 1432.2 \\
\hline r-about & & 2.5 & 3.4 & 4.6 & 6.8 & 23.2 & 165.5 & 312.3 & 459.9 & 618.8 \\
\hline signal & & 4.1 & 6.5 & 8.5 & 10.4 & 16.6 & 20.7 & 26.4 & 40.2 & 139.5 \\
\hline stop & \multirow{4}{*}{600} & 2.2 & 4.6 & 93.6 & 174.6 & 234.3 & 283.6 & 324.7 & 402.6 & 515.3 \\
\hline $\operatorname{mini}$ & & 1.9 & 3.0 & 8.3 & 128.4 & 270.2 & 427.5 & 706.4 & 993.2 & 1272.2 \\
\hline r-about & & 2.0 & 2.9 & 3.9 & 5.4 & 8.6 & 49.0 & 199.3 & 349.4 & 501.1 \\
\hline signal & & 3.6 & 5.6 & 7.1 & 8.5 & 10.2 & 17.1 & 22.5 & 37.4 & 138.7 \\
\hline stop & \multirow{4}{*}{400} & 1.4 & 1.8 & 9.2 & 77.7 & 129.2 & 176.8 & 218.7 & 297.1 & 410.0 \\
\hline $\operatorname{mini}$ & & 1.4 & 2.3 & 4.1 & 43.9 & 187.8 & 337.3 & 575.0 & 828.5 & 1099.9 \\
\hline r-about & & 1.6 & 2.4 & 3.3 & 4.5 & 6.3 & 10.9 & 65.7 & 220.2 & 375.9 \\
\hline signal & & 3.1 & 4.6 & 5.6 & 6.5 & 7.9 & 14.5 & 19.9 & 33.1 & 138.7 \\
\hline stop & \multirow{4}{*}{200} & 0.8 & 0.9 & 1.1 & 2.3 & 31.1 & 69.9 & 112.5 & 191.4 & 304.6 \\
\hline $\operatorname{mini}$ & & 1.0 & 1.8 & 3.0 & 6.7 & 89.6 & 242.6 & 483.6 & 738.7 & 991.5 \\
\hline r-about & & 1.2 & 2.0 & 2.9 & 3.9 & 5.3 & 7.5 & 12.9 & 67.0 & 227.8 \\
\hline \multirow[t]{4}{*}{ signal } & & 2.3 & 3.1 & 3.9 & 4.9 & 6.3 & 12.8 & 17.5 & 29.2 & 136.8 \\
\hline & & 400 & 800 & 1200 & 1600 & 2000 & 2400 & 2800 & 3200 & 3600 \\
\hline & & \multicolumn{9}{|c|}{ Main 2-way (veh/hr) } \\
\hline & & & \multicolumn{2}{|c|}{ Mini circle } & Traffi & ignal & \multicolumn{2}{|c|}{ Roundabout } & \multicolumn{2}{|c|}{ Stop } \\
\hline
\end{tabular}

signal already exists, or when there is insufficient road reserve, or when any of the worst locations for roundabouts listed in the "Guidelines for Roundabouts" section above are present.

In conclusion, this research finds that:

- An average of two vehicles in a queue $(2 \mathrm{Q})$ at a stop street is the warrant to consider conversion to roundabouts or mini-circles.

- When the total queue on all approaches to the roundabout reaches around ten (10Q), that is an indication that the roundabout is nearing capacity and that traffic signals and possibly road widening should be considered.

- There is a wide range between the $2 \mathrm{Q}$ and 10Q conditions where roundabouts would be the optimal form of control, and they could operate well even outside this range.

- The total intersection volume range over which roundabouts are optimal is large, roughly from 1000 to 2400 vehicles per hour, indicating that, with average traffic growth, the roundabout would be optimal for around 30 years without modification.

It is further recommended that all-way stops are never used in urban areas, and where they exist they should be replaced with mini-circles or, if need be, roundabouts. Over and above the unnecessary delay and queues caused by all-way stops, motorists regularly ignore the sign and proceed without stopping, thereby effectively turning the control into a yield from all sides.

Formally recognising this typical behaviour by converting the all-way stop into a minicircle or roundabout will turn offenders into law-abiding citizens.

\section{REFERENCES}

COTO (Committee of Transport Officials) 2001. South African Road Traffic Signs Manual. Vol 3, Chapter 2. Pretoria: National Department of Transport. PWV Consortium 2001. Roundabouts (traffic circles) as intersection control devices on provincial roads. BL 99/5 Draft Report. Pretoria: Gauteng Department of Roads and Transport.

Sampson, J D 1992. Warrants for traffic signals. $\mathrm{PhD}$ Thesis. Johannesburg: University of the Witwatersrand.

Sampson, J D 1999. Queue-based traffic-signal warrants: The 4Q/6Q Warrant. Institute of Transportation Engineers (ITE) Journal, 69, (4): 30-32.

Sampson, J D 2018. AutoJ Traffic Engineering Software, Version EAutoJ 1808, Sandton, South Africa. Available from: sampsonjds@gmail.com; www.autojtraffic.com. 
Sampson, J D \& Meijer M 1999. The use of modern roundabouts on provincial roads. Proceedings, 18th South African Transport Conference, Pretoria.

TRB (Transportation Research Board) 2000.

Roundabouts: An Informational Guide. National

Cooperative Highway Research Program (NCHRP)

Report 672. Washington, DC: National Research

Council.

TRB (Transportation Research Board) 2010. Highway

Capacity Manual. Washington, DC: National

Research Council.

US Department of Transport 2009. Manual of Uniform Traffic Control Devices (MUTCD), Washington, DC:

Federal Highway Administration.

\section{APPENDIX A: AUTOJ SUMMARY EXAMPLE}

A typical AutoJ software summary (Sampson 2018) is given in Appendix A below. In the summary the level of service using delay and $\mathrm{V} / \mathrm{C}$ numbers as performance measures is colour-coded, with the optimal control(s) shown in green-shaded blocks.

AutoJ uses a performance index to take into account that the control device must operate over 24 hours and not just the peak hour. The performance index weights the control's efficiency as follows:

- maximum $\mathrm{V} / \mathrm{C}$ of any movement (more critical than delay in peak hours): $18 \%$ AM and PM peaks, 4\% off-peak average $\mathrm{V} / \mathrm{C}$ of intersection combining peak and off-peak: $10 \%$

- maximum delay to any movement (delay should be minimised if $\mathrm{V} / \mathrm{C}$ is not a concern, hence off-peak is favoured): 4\% AM and PM peaks, $7 \%$ off-peak

- overall intersection delay per vehicle during worst period: $10 \%$

maximum queue on any approach: 6\% AM and PM peaks, 3\% off-peak

- total queue adding AM, PM and off-peak: $10 \%$.

\section{APPENDIX A}

Main Road (two lanes per direction) and Side Street (one lane per direction)

$2 \times 1$ with added right turn lane if a signal

Summary

\begin{tabular}{|c|c|c|c|c|c|c|c|c|c|c|c|c|c|c|c|c|c|}
\hline & & & \multicolumn{5}{|c|}{ Volume / capacity (maximum) } & \multicolumn{5}{|c|}{ Delay / vehicle (maximum) } & \multicolumn{5}{|c|}{ Queue (maximum) } \\
\hline & Weighting & $100 \%$ & & $18 \%$ & $4 \%$ & $18 \%$ & $10 \%$ & & $4 \%$ & $7 \%$ & $4 \%$ & $10 \%$ & & $6 \%$ & $3 \%$ & $6 \%$ & $10 \%$ \\
\hline \multicolumn{3}{|c|}{ Perf index } & Peds & AM & Off & PM & $\mathrm{i} / \mathrm{s}$ ave & Peds & AM & Off & PM & $\mathrm{i} / \mathrm{s}$ ave & Peds & AM & Off & PM & $i / s$ sum \\
\hline Best ICD & $\mathrm{RR}$ & $86 \%$ & 0.00 & 0.65 & 0.22 & 0.47 & 0.31 & 2 & 10 & 7 & 8 & 8 & 0.0 & 1.2 & 0.5 & 1.3 & 10.4 \\
\hline Best signal & n3 & $63 \%$ & 0.00 & 0.47 & 0.25 & 0.54 & 0.32 & 38 & 21 & 20 & 28 & 17 & 0.0 & 2.1 & 1.1 & 3.0 & 21.5 \\
\hline \multicolumn{2}{|l|}{ Control type } & $\mathrm{PI}$ & 0.00 & AM & Off & PM & $\mathrm{i} / \mathrm{s}$ ave & Peds & AM & Off & PM & $\mathrm{i} / \mathrm{s}$ ave & Peds & AM & Off & PM & $i / s$ sum \\
\hline \multirow{5}{*}{ Priority } & Xns & $32 \%$ & 0.00 & 0.97 & 0.37 & 1.19 & 0.48 & 85 & 68 & 11 & 374 & 65 & 0.0 & 10.8 & 0.9 & 28.0 & 52.0 \\
\hline & Xwe & $48 \%$ & 0.00 & 1.27 & 0.34 & 0.77 & 0.29 & 100 & 465 & 10 & 22 & 71 & 0.0 & 34.9 & 0.3 & 0.4 & 40.5 \\
\hline & $X X$ & $37 \%$ & 0.00 & 1.09 & 0.29 & 0.73 & 0.53 & & 236 & 11 & 19 & 96 & 0.0 & 37.8 & 0.9 & 3.1 & 61.2 \\
\hline & $\mathrm{CC}$ & $57 \%$ & 0.00 & 0.72 & 0.33 & 0.92 & 0.51 & 6 & 11 & 6 & 28 & 17 & 0.0 & 1.7 & 0.5 & 4.5 & 15.5 \\
\hline & $\mathrm{RR}$ & $86 \%$ & 0.00 & 0.65 & 0.22 & 0.47 & 0.31 & 2 & 10 & 7 & 8 & 8 & 0.0 & 1.2 & 0.5 & 1.3 & 10.4 \\
\hline 2 stage & 2 & $52 \%$ & 0.00 & 0.41 & 0.25 & 1.14 & 0.31 & 33 & 15 & 15 & 349 & 58 & 0.0 & 2.4 & 0.7 & 26.2 & 41.6 \\
\hline \multirow{6}{*}{3 stage } & $3 n s$ & $60 \%$ & 0.00 & 0.46 & 0.26 & 0.56 & 0.34 & 38 & 20 & 20 & 28 & 19 & 0.0 & 3.2 & 1.1 & 3.1 & 24.6 \\
\hline & 3 we & $40 \%$ & 0.00 & 0.46 & 0.35 & 1.78 & 0.37 & 38 & 20 & 20 & 904 & 140 & 0.0 & 3.2 & 1.1 & 67.8 & 88.5 \\
\hline & n3 & $63 \%$ & 0.00 & 0.47 & 0.25 & 0.54 & 0.32 & 38 & 21 & 20 & 28 & 17 & 0.0 & 2.1 & 1.1 & 3.0 & 21.5 \\
\hline & s4 & $39 \%$ & 0.00 & 0.47 & 0.36 & 1.81 & 0.36 & 38 & 21 & 20 & 921 & 141 & 0.0 & 3.4 & 1.1 & 69.0 & 88.1 \\
\hline & w3 & $39 \%$ & 0.00 & 0.47 & 0.36 & 1.82 & 0.37 & 38 & 21 & 19 & 922 & 143 & 0.0 & 3.4 & 1.1 & 69.2 & 89.4 \\
\hline & e3 & $39 \%$ & 0.00 & 0.47 & 0.36 & 1.82 & 0.39 & 38 & 21 & 21 & 922 & 143 & 0.0 & 3.4 & 1.1 & 69.2 & 90.8 \\
\hline \multirow{9}{*}{4 stage } & 4nswe & $51 \%$ & 0.00 & 0.50 & 0.34 & 0.64 & 0.38 & 43 & 25 & 25 & 33 & 25 & 0.0 & 4.1 & 1.4 & 4.4 & 31.6 \\
\hline & n4we & $53 \%$ & 0.00 & 0.54 & 0.28 & 0.63 & 0.36 & 43 & 27 & 25 & 33 & 21 & 0.0 & 2.8 & 1.5 & 4.3 & 28.0 \\
\hline & s4we & $32 \%$ & 0.00 & 0.52 & 0.49 & 2.88 & 0.44 & 43 & 26 & 25 & 1283 & 195 & 0.0 & 4.2 & 1.5 & 96.2 & 120.6 \\
\hline & w4ns & $50 \%$ & 0.00 & 0.52 & 0.35 & 0.67 & 0.38 & 43 & 26 & 24 & 33 & 26 & 0.0 & 4.2 & 1.5 & 4.7 & 31.3 \\
\hline & e4ns & $49 \%$ & 0.00 & 0.52 & 0.35 & 0.67 & 0.40 & 43 & 26 & 25 & 33 & 26 & 0.0 & 4.2 & 1.5 & 4.7 & 32.7 \\
\hline & nw4 & $53 \%$ & 0.00 & 0.54 & 0.29 & 0.66 & 0.35 & 43 & 27 & 25 & 33 & 22 & 0.0 & 2.9 & 1.6 & 4.6 & 27.5 \\
\hline & ne4 & $52 \%$ & 0.00 & 0.54 & 0.29 & 0.66 & 0.37 & 43 & 27 & 26 & 33 & 22 & 0.0 & 2.9 & 1.6 & 4.6 & 29.1 \\
\hline & sw4 & $31 \%$ & 0.00 & 0.54 & 0.50 & 2.89 & 0.44 & 43 & 27 & 25 & 1287 & 196 & 0.0 & 4.4 & 1.5 & 96.5 & 120.2 \\
\hline & se4 & $31 \%$ & 0.00 & 0.54 & 0.50 & 2.89 & 0.45 & 43 & 27 & 26 & 1287 & 196 & 0.0 & 4.4 & 1.5 & 96.5 & 121.8 \\
\hline \multirow{6}{*}{$\begin{array}{l}\text { Separate } \\
\text { (split) stage }\end{array}$} & $n-s-3$ & $49 \%$ & 0.00 & 0.56 & 0.33 & 0.57 & 0.42 & 43 & 34 & 28 & 33 & 29 & 0.0 & 4.5 & 2.0 & 3.8 & 37.4 \\
\hline & $w-e-3$ & $34 \%$ & 0.00 & 0.53 & 0.39 & 1.89 & 0.43 & 43 & 32 & 27 & 965 & 154 & 0.0 & 4.3 & 1.5 & 72.4 & 101.7 \\
\hline & $n-s-4 w e$ & $44 \%$ & 0.00 & 0.61 & 0.36 & 0.62 & 0.45 & 48 & 40 & 33 & 38 & 34 & 0.0 & 5.4 & 2.4 & 4.6 & 44.2 \\
\hline & w-e-4ns & $43 \%$ & 0.00 & 0.58 & 0.38 & 0.75 & 0.44 & 48 & 37 & 32 & 38 & 33 & 0.0 & 5.2 & 1.9 & 5.9 & 41.7 \\
\hline & $n-s-w-e-4$ & $37 \%$ & 0.00 & 0.73 & 0.44 & 0.78 & 0.55 & 48 & 45 & 36 & 42 & 40 & 0.0 & 6.4 & 2.7 & 6.2 & 52.2 \\
\hline & Optimums & $86 \%$ & & 0.41 & 0.22 & 0.47 & 0.29 & & 10 & 6 & 8 & 8 & & 1.2 & 0.3 & 0.4 & 10.4 \\
\hline Colour code & Near best & Best & & \multicolumn{4}{|c|}{ Within $10 \%$ of optimum } & LOS & $A-B$ & $C-D$ & $E$ & $\mathrm{~F}$ & & & & & \\
\hline
\end{tabular}

